\title{
RELEVO E DESENVOLVIMENTO DE TÓPICO DISCURSIVO
}

\author{
LUIZ CARLOS TRAVAGLIA $^{1}$ \\ (UFU)
}

\begin{abstract}
RESUMÉ Dans cet article, notre objectif est de relever et d'énumérer les éléments ou types d'éléments sur lesquels porte le relief positif (proéminence) ou négatif (rebaissement) au cours du développement du topique discursif et comment cela se passe. Pour cela nous reprenons le concept de topique discursifétablie pour Jubran, Travaglia et al. (1991) et les études de relief (concept, recours, types, raisons et fonctions) developpées chez Travaglia (1999).
\end{abstract}

\section{INTRODUÇÃO}

A constituição e funcionamento discursivo do texto na comunicação se faz para o desenvolvimento de um dado tópico discursivo. A forma com que o texto se constitui depende de fatores vários que a teoria lingüística tem levantado e observado, buscando descrever e explicar, e que não cabe reapresentar aqui, embora possamos lembrar alguns: o contexto sócio-históricoideológico; a situação imediata de comunicação, incluindo o quando e onde, os sujeitos da interação e os lugares sociais que ocupam e suas formas sujeito, os objetivos que se tem na interação (o para que, o porque comunicar); o conhecimento de mundo e lingüístico dos sujeitos da interação; o conhecimento realmente ou supostamente partilhado pelos interlocutores, etc. Muitos elementos da constituição do texto, do modo como ele se constitui e funciona têm sido examinados por diferentes teorias. Alguns seriam: a coesão; a coerência; a argumentação; a referenciação; o seqüenciamento e ordenação de informações e o seu agrupamento em blocos; a informação selecionada ser apresentada como nova ou conhecida; a progressão textual; as categorias de textos e suas características; as superestruturas; etc. Neste estudo o que queremos focalizar é o elemento da constituição do texto que chamamos de relevo (Travaglia-1999) em sua relação com o desenvolvimento do tópico, com o objetivo primeiro de levantar os tipos de elementos do texto sobre os quais o relevo pode incidir. Para tal vamos iniciar dizendo algo que cremos ser necessário: o que entendemos por tópico discursivo e por relevo.

\section{TÓPICO DISCURSIVO E RELEVO}

1.1. Estamos entendendo o tópico discursivo tal como definido e caracterizado pelo grupo da abordagem textual-interativa na Gramática do Português Falado (Jubran, Travaglia et alii- 1991). O tópico discursivo tem a ver com o conteúdo do texto.

${ }^{1}$ Professor do Instituto de Letras e Lingüística da Universidade Federal de Uberlândia. E-mail: lctravaglia@ufu.br. 
"Tomado no sentido geral de "acerca de", o tópico manifesta-se ......... mediante enunciados formulados a respeito de um conjunto de referentes explícitos ou inferíveis, concernentes entre si e em relevância num determinado ponto da mensagem."(JUBRAN, TRAVAGLIA et alii, 1991, p. $361)$.

O tópico tem como propriedades definidoras:

A) "a centração que abrange os traços de:

a) concernência: relação de interdependência semântica entre os enunciados _ implicativa, associativa, exemplificativa ou de outra ordem _ _ pela qual se dá sua integração no referido conjunto de referentes explícitos ou inferíveis;

b) relevância: proeminência desse conjunto, decorrente da posição focal assumida pelos seus elementos;

c) pontualização: localização desse conjunto, tido como focal, em determinado momento da mensagem.”.’(JUBRAN, TRAVAGLIA et alii, 1991, p. 361,362)

B) organicidade: a topicalidade é vista como "um princípio organizador do discurso, que apresenta, portanto, no plano de sua realização, uma estrutura passível de ser identificada e analisada."."(JUBRAN, TRAVAGLIA et alii, 1991, p. 362).

Desse modo, o tópico é visto como unidade que apresenta como propriedades fundamentais a centração e a organicidade. A organicidade

é manifesta por relações de interdependência que se estabelecem simultaneamente em dois planos: no plano hierárquico, conforme as dependências de super-ordenação e sub-ordenação entre tópicos que se implicam pelo grau de abrangência do assunto"2; no plano seqüencial, de acordo com articulações intertópicas em termos de adjacências ou interposições na linha discursiva". ."(JUBRAN, TRAVAGLIA et alii, 1991, p. 362,363)

Portanto no desenvolvimento de um tópico super-ordenado do texto como um todo, há agrupamentos mais delimitados em porções do texto (escrito ou oral) que chamamos de segmentos tópicos, com tópicos sub-ordenados. A relevância que é um traço da centração se estabelece em relação a estes tópicos de diferentes níveis hierárquicos como uma focalização num dado trecho da mensagem em determinados referentes. Não se relaciona com o que chamamos de relevo.

1.2- O relevo é entendido ${ }^{3}$ como o fenômeno de o falante, ao dizer, ao produzir seu texto, formulando-o, construindo-o, constituindo-o:

a) dar destaque a determinados elementos dentro desse mesmo texto, colocando-os em proeminência em relação ao outros. Neste caso, tem-se um relevo positivo a que denominamos proeminência, ou

${ }^{2}$ Essa organização hierárquica compõe o que se chamou de Quadro Tópico (Cf. JUBRAN, TRAVAGLIA et alii, 1991, p. 363, 364, item 3.1).

${ }^{3}$ Cf. Travaglia (1999). 
Cadernos de Estudos Lingüísticos 48(1) - Jan./Jun. 2006

b) fazer um rebaixamento, "ocultamento" de determinados elementos em relação aos outros. Neste caso tem-se um relevo negativo a que denominamos rebaixamento.

Os elementos objeto de relevo podem ser "partes" do conteúdo ou certos tipos de conteúdo que compõem o tópico discursivo: entidades, informações, relações, etc.; ou ainda aspectos formais ou estratégias no desenvolvimento do tópico: recursos lingüísticos, mudanças ou retomadas de tópicos. Os elementos sobre os quais o relevo atua podem ser elementos isolados do conteúdo ou conjuntos de elementos ou os elementos de um dado tipo. Assim, por exemplo, podem ser objeto de relevo: "a) os episódios de uma narrativa, constituídos por ações (tipo de conteúdo) em relação ao cenário, descrições de personagens, ações de pano de fundo; b) ações em relação a outras por razões emotivas; c) determinados conceitos; d) um argumento em relação a outro; e) a introdução de um novo subtópico ou a volta a um subtópico; f) determinadas relações entre proposições; g) uma forma de dizer em relação a outra .........., etc." .”(TRAVAGLIA, 1999, p. 77 e 128-nota 1, adaptada).

Com relação ao relevo, os elementos do texto podem ter um status proeminente, normal ou rebaixado. No rebaixamento, por alguma razão, o produtor do texto quer que "determinado(s) elemento(s) do texto passe(m) despercebidos ou não tenham a atenção do interlocutor, não porque sejam sem importância, mas quase sempre por questões de argumentação ou questões ligadas às relações entre ele e o interlocutor.’(TRAVAGLIA, 1999, p.77 e 128-nota 2). Por tudo isto o rebaixamento é muito difícil de observar tanto nos textos orais quanto escritos. Nos orais não observamos nenhuma ocorrência, quase sempre porque o recurso usado é a altura da voz e, nos corpora analisados, geralmente se tornam inaudíveis e não são transcritos; já nos textos escritos encontramos algumas ocorrências de rebaixamento. Ao contrário a proeminência acontece com uma freqüência considerável, sobretudo na fala.

Um caso muito comum de rebaixamento acontece em textos publicitários veiculados na televisão e/ou na mídia impressa. Este caso de rebaixamento acontece da seguinte maneira: a publicidade chama a atenção para o produto ou serviço que vende e destaca suas qualidades ou outros elementos que possam servir e são usados como argumentos para persuadir o consumidor a adquirir produtos e serviços ou a adotar determinadas atitudes ou idéias. Ao mesmo tempo ela é obrigada, por lei, a explicitar determinadas informações que nem sempre são favoráveis à persuasão do consumidor. Então ela o faz, utilizando um rebaixamento. O recurso usado é, geralmente, o tamanho da letra. Nas propagandas televisivas, por exemplo, a parte positiva é apresentada com muito destaque por meio de letras grandes com efeitos especiais ou não (cor, mudança de cor, movimentos, etc) e/ou pelas imagens e/ou por um locutor que fala em cena ou ausente, ouvindo-se apenas a sua voz, freqüentemente sublinhados por uma música adequada a ajudar a proeminência. Já a parte negativa é posta em texto escrito com letras proporcionalmente muito pequenas (nunca é dita pelo locutor), geralmente em posição horizontal na parte inferior da tela ou em posição vertical na lateral esquerda da tela. Como as propagandas televisivas geralmente são rápidas e o consumidor está centrado em observar primeiro os elementos em proeminência, quase nunca ele vê ou lê a parte negativa. Mesmo que a perceba, muito dificilmente a poderá ler por duas razões: o tamanho da letra que, com freqüência, a torna ilegível e/ou o pouco tempo que tem para fazê-lo, quando chega a perceber esta parte do texto. Em (1), descrevemos uma propaganda televisiva em que isto ocorre, lembrando que isto acontece em uma proporção bastante elevada das publicidades em televisão. Em (2), reproduzimos uma publicidade do UNIBANCO / AIG Seguros e Previdência também com o tipo de rebaixamento que especificamos acima. 
(1) Desde o lançamento do iogurte ACTIVIA, a Danone, seu fabricante, vem destacando suas qualidades como um regulador intestinal. A campanha publicitária parece dirigida sobretudo ao consumidor feminino, daí se dizer também de consequiências na beleza (geralmente pele melhor, mais bonita) do efeito salutar do produto. Em 2006, foi posta no ar uma publicidade em que uma mulher jovem, com jaleco branco, insinuando tratar-se de um profissional da saúde, propõe um desafio: que o consumidor tome ACTIVIA por 15 dias seguidos e que, se no final desse tempo o seu intestino não melhorar significativamente o funcionamento, a Danone devolve o dinheiro gasto pelo consumidor. Tudo é apresentado com imagens muito bem elaboradas do produto e também do seu efeito (aparece uma silhueta frontal da região abdominal de um corpo humano feminino com uma grande seta composta de pontos com movimentos para baixo, sugerindo o bom funcionamento do intestino). Na parte inferior da tela aparece em rebaixamento o seguinte texto:

"O consumo deve ser associado a uma dieta equilibrada e hábitos saudáveis."

Ou seja, aquilo que resguarda o produtor de eventuais problemas (inclusive processos) com os consumidores e que pode revelar que o efeito propalado do produto, na verdade, pode não ocorrer é apresentado, por exigências legais, mas de tal maneira que uma grande proporção de expectadores/consumidores nem mesmo percebe a presença desta parte do texto ${ }^{4}$. Além disso, o que resguarda o produtor é expresso de maneira pouco específica, pois facilmente se pode dizer que alguém não manteve uma dieta equilibrada e hábitos saudáveis, a não ser que haja no "desafio ACTIVIA" uma especificação e controle por parte do produtor anunciante.

(2) A publicidade do UNIBANCO / AIG Seguros e Previdência da imagem abaixo foi veiculada em duas páginas lado a lado da revista VEJA, edição 1954, ano 39, n 17, 03/05/2006: pp. 6 e 7. A publicidade contém os seguintes textos verbais:

a) No canto inferior direito, em letras grandes:

UNIBANCO / AIG Seguros \& Previdência

Nem parece seguradora.

b) No canto inferior esquerdo acima da linha, em letras médias: Na Unibanco AIG, sua indenização chega a jato. (O que se relaciona à figura de um homem montado num foquete e entregando um cheque ao carro antropomorfizado - representando provavelmente seu proprietário - e apresentado com uma expressão de agradável surpresa).

c) Texto maior no pé da página abaixo da linha, em letras um pouco menores do que as do texto de b, mas bem legíveis: Pagamento da indenização em tempo recorde, só na Unibanco AIG. Em caso de perda total, você recebe em até 5 dias úteis após a entrega da documentação completa*. E se o prazo não for cumprido, você recebe, além da indenização, o valor que pagou pelo seguro. Você pode ainda pagar seu seguro em até 5 vezes sem juros e, quando utilizar uma de nossas oficinas referenciadas, tem $25 \%$ de desconto na franquia. Consulte agora seu corretor ou procure uma de nossas agências. Unibanco AIG Seguros. Ágil. Nem parece seguradora.

${ }^{4}$ Num teste rápido pedimos a cinco pessoas que assistissem a propaganda. Depois quando lhes perguntamos o que estava escrito na parte inferior da tela, nenhuma tinha registrado a existência dessa parte do texto. 
Cadernos de Estudos Lingüísticos 48(1) - Jan./Jun. 2006

d) Texto da linha vertical na lateral esquerda da foto, em letra bem miúda, com mais ou menos $1 \mathrm{~mm}$ de altura, esclarecendo o asterisco colocado no texto de $\mathbf{c}$ acima: * O pagamento das indenizações está condicionado às cláusulas estabelecidas na Condições Gerais do seguro contratado. CNPJ 33.166.158/0001-95. Códigos Susep 005.0077/01 e 10.000.600/01-68.

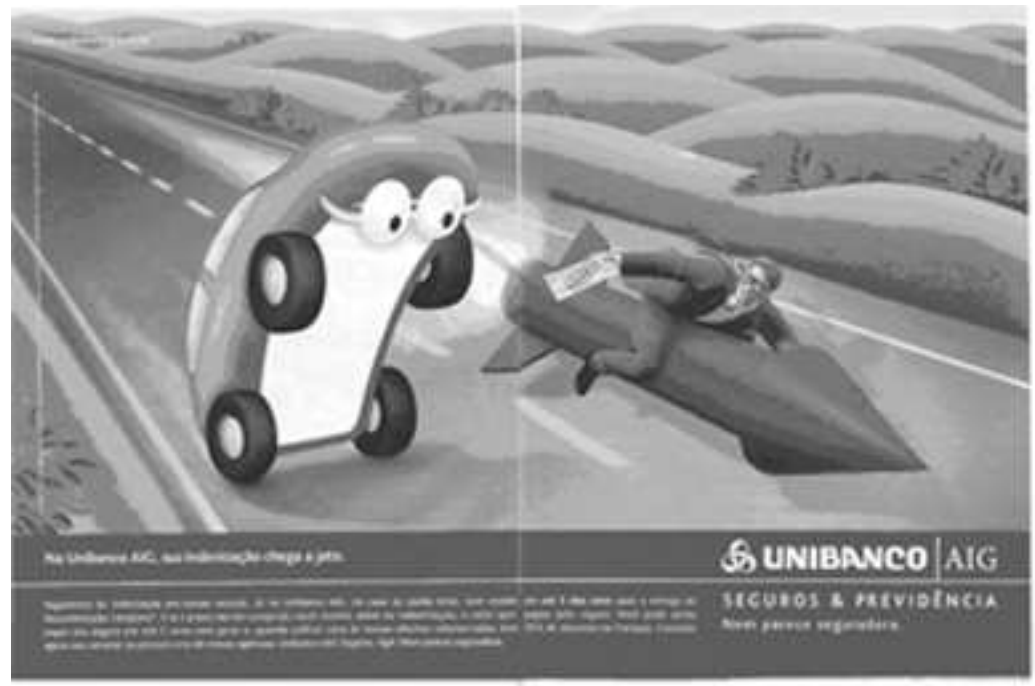

Como se pode ver no exemplo (2) a informação em letras miúdas, visualmente de difícil leitura, contém uma restrição não totalmente especificada às vantagens apresentadas pela imagem e pelos outros textos verbais sobre a rapidez de pagamento da indenização pelo seguro. Portanto tem-se um rebaixamento do tipo que comentamos ocorrer em textos publicitários.

Talvez também se possa considerar como um caso de rebaixamento as cláusulas de contratos que vêm em letras muito pequenas, dificultando a leitura, geralmente porque contêm elementos desfavoráveis ao contratante, por exemplo, de um serviço (de telefonia, planos de saúde, etc.), ou de produtos financeiros (financiamentos, empréstimos, etc.) aos quais o contratado não quer que o contratante dê muita atenção ou perceba.

1.3. O relevo aparece por razões diversas e com funções variadas (Cf. TRAVAGLIA, 1999). No desenvolvimento do tópico, o relevo vai marcar avaliações sobre o conteúdo do texto e sobre elementos da interação. Ao apresentar esta avaliação o produtor do texto direciona para uma visão do conteúdo e para aspectos da interação o que representa uma dimensão argumentativa em sentido amplo do texto.

\section{RELEVO E DESENVOLVIMENTO DO TÓPICO}

Neste item queremos lembrar alguns aspectos relacionados ao relevo já desenvolvidos em Travaglia (1999) e necessários à boa compreensão do que apresentamos aqui. 


\subsection{Instrução ao interlocutor}

Como ficou dito em 1.3, no desenvolvimento do tópico, o relevo (proeminência ou rebaixamento), marca avaliações sobre elementos mais específicos do texto ou sobre tipos de elementos do texto ou sobre porções do conteúdo do texto, fazendo um direcionamento da atenção do interlocutor. O relevo, funciona, para o interlocutor (ou o produtor quer que funcione):

a) no caso do relevo positivo ou proeminência, como uma instrução do tipo: para mim é importante tal elemento ou você deve dar importância e atenção maior a tal elemento do conteúdo (entidade, conceito, relação, argumento, etc.); a tal tipo de elemento (episódios, ações, características, conclusão, argumento, etc) ou a determinadas porções do texto e o que elas contêm (parte do tópico que ali se desenvolve);

b) no caso do relevo negativo ou rebaixamento, algo como: isto não é importante, não dê importância a estes elementos do texto ou ao que digo agora ou em tal porção do texto.

\subsection{Tipos de relevo}

Como já dissemos em Travaglia (1999) temos as seguintes formas de relevo que não são excludentes entre si:

1) $\mathrm{O}$ relevo quanto à direção pode ser, como vimos, positivo (proeminência) ou negativo (rebaixamento).

2) Quanto à natureza temos as seguintes formas de relevo:

a) o contraste entre figura (primeiro plano) e fundo (segundo plano) que tem a ver com a relevância temática, que, para Fuchs (1987), seria a relação de uma predicação com um quadro temático compartilhado pelo interlocutores;

b) a organização e apresentação das informações como informações essenciais / principais por um lado e informações secundárias por outro;

c) indicação da relevância pragmática de uma situação, de algo no texto (acontecimento, estado, comentário) para a situação presente (o aqui e o agora) ou para um ponto de referência;

d) os fatos de focalização que se refere ao relevo que incide sobre um dado tipo de elemento do conteúdo do texto como:

- Na narrativa, foco nos acontecimentos ou no participante (personagem) ou no falante (narrador);

- Na descrição, foco em características de tipos diferentes: características psicológicas ou físicas, transitórias ou permanentes, elementos ou atributos;

- Na dissertação e na argumentação, foco em conceitos ou relações, em argumentos ou não argumentos;

- Na injunção, foco na ação a executar, no executante, no ato de determinar ou na justificativa;

- Em qualquer tipo de texto, foco na informação nova.

3) Quanto ao plano em que o relevo se instancia e que se caracterizam pela razão do relevo, este pode ser emocional, argumentativo ou ideacional/cognitivo e ainda interacional. 


\subsection{Recursos marcadores de relevo}

Em Travaglia (1999), foi feito um levantamento de recursos marcadores ou responsáveis pelo relevo sobretudo na língua oral. Aqui vamos apenas listar esses recursos, comentando e exemplificando apenas aqueles que não o foram em Travaglia (1999). Estes recursos são de vários níveis e planos da língua e alguns não são lingüísticos como o tipo e tamanho da letra na língua escrita. A seguir enumeramos os recursos de relevo que encontramos, sem qualquer pretensão de exaustividade, dividindo-os pela modalidade de língua em que atuam:

\section{I) Apenas na língua oral}

1) Recursos fônicos: a entonação; a altura da $\mathrm{voz}^{5}$; velocidade ou ritmo da fala; o alongamento de sons sobretudo de vogais; onomatopéia de uma "música de fundo" (tcham, tcham, tcham);

II) Apenas na língua escrita

1) Recursos gráficos: tipo e tamanho da letra; cor da letra; formatação (negrito, itálico, sublinhado) disposição na página;

III) Atuantes na língua oral e escrita

1) Recursos fônicos: recorte silábico ou silabação ;

(3) "esses saberes fundamentais sobre o jurídico ... são ciências"... esses três saberes... não é? são ciências no sentido de que ... representam um conjunto or-de-na-do de definições... CLASSIFICAÇÕES e proposições... sobre relações... pertinentes ao direito..." (NURCEF REC 337: 290-294) (língua oral)

(4) "Que atordoamento vazio me esfalfa o cérebro?

Devo tomar qualquer coisa ou suicidar-me?

Não: vou existir. Arre! Vou existir.

E - xis - tir...

E - xis - tir..."

(Fernando Pessoa, O Eu profundo e os outros Eus, p. 265) (língua escrita)

2) Recursos léxicos: o uso de itens lexicais (insistir, sublinhar, destacar, salientar, grifar, etc.); uso de expletivos (ser ... que, ser que); uso de verbos gramaticais de relevo (como o verbo ser); uso de outros expletivos (se, alguns casos de objeto direto preposicionado).

${ }^{5}$ É comum na língua escrita a maior altura da voz ser representada pela colocação do item pronunciado com maior altura em letra maiúscula com ou sem negrito.

${ }^{6}$ A silabação aparece na língua escrita, mas será sempre uma tradução do modo como a(s) palavra(s) foi (foram) / devem ser pronunciadas.

${ }^{7}$ Essas abreviaturas indicam que o exemplo foi retirado de um inquérito do corpus do NURC (Projeto da Norma Urbana Culta), e informam: a) o tipo do inquérito (D2: Diálogo entre dois informantes; DID: Diálogo entre informante e documentador; EF: Elocução Formal ); b) a cidade onde foi realizado o inquérito (SP: São Paulo; RE: Recife; POA: Porto Alegre; SSA: Salvador e RJ: Rio de Janeiro); c) o número do inquérito logo após a cidade; d) a(s) página(s) do inquérito em que o exemplo se encontra. 
3) Recursos morfológico-categoriais: aspecto verbal; tempo verbal;

4) Recursos sintáticos: topicalização; uso de parênteses; repetição; orações principais; orações reduzidas e adjetivas;

5) Marcadores conversacionais;

6) A mudança de código, ou seja, a passagem de uma variedade de língua para outra.

7) A posição do elemento no texto ou segmentos tópicos. (Ver 3.8.1).

8) Operadores argumentativos. Veja exemplos (5) a (7). Em (5), o operador argumentativo "até" apresenta o fato de "os colegas perderem a paciência com as dúvidas de Edmundo" como o argumento mais forte/importante para a conclusão de que Edmundo era um aluno muito difícil. Em (6), o operador argumentativo "aliás", apresenta o argumento a posteriori, mas dá-lhe um destaque tornando-o o mais importante e por sua causa o interlocutor A, nem devia ter feito o questionamento que fez. Em (7), novamente o operador argumentaivo "até" dá proeminência a um argumento que emocionalmente o falante considera evidência do cuidado que algumas pessoas têm na preparação e realização de refeições que é o subtópico em desenvolvimento.

(5) Edmundo foi aluno muito difícil. Até os colegas perdiam a paciência com as suas dúvidas. Alguém devia ter tentado enganá-lo, um dia, para que ele assim desconfiasse de tudo e de todos. (Meirelles, Cecília. "Edmundo, o céptico" in Quadrante. Rio de Janeiro: Editora do Autor, 1962, p. 122.)

(6) A- Por que vocês não convidaram o João para ir pescar com vocês?

B- Ele não estava aqui. Aliás você sabe que ele não gosta de pescar.

(7) I1- ........eu tenho um conhecido, aliás, um amigo comum nosso que ele é especialista em comida internacional então vai faze(r) uma comida chinesa, indiana, qualque(r) coisa até incenso ele queima, bah, só falta música ambiental, só falta eu me vesti(r) a rigor.(NURCD2 POA 291:. 125-129)

\section{ELEMENTOS EM RELEVO}

Neste estudo nossa intenção é chamar a atenção, mais especificamente, para o tipo de elemento que é objeto de relevo positivo ou negativo. Nos subitens a seguir, buscamos elencar os tipos de elementos sobre os quais o relevo pode incidir e que pudemos observar até o momento.

3.1. Relevo incidente sobre conceitos e modelos cognitivos globais (frames, esquemas, planos e scripts) ativados no texto por substantivos, verbos, adjetivos e sintagmas nominais, sobre os quais incide quase 50\% do relevo pela altura da voz na língua falada (Cf. Travaglia,1999, p. 95). Na língua escrita, geralmente o relevo desses conceitos é feito por recursos gráficos (geralmente negrito, itálico, sublinhado), como se pode observar neste artigo mesmo, em cuja construção se está utilizando desse recurso. Em (3), (8) a (13), temos exemplos na língua oral. Em (3), uma professora dá relevo a conceitos que considera fundamentais e importantes para o subtópico que desenvolve no momento em que fala, portanto um relevo de natureza ideacional/ cognitiva. Em (8), o falante, emocionalmente, coloca em relevo uma dada característica de avaliação de algo sobre o qual está falando. Em (10), o relevo incide sobre a existência ou não de algo que é fundamental para o entendimento do tópico tratado: a distinção entre ciência do normativo e ciência normativa. Em (11), a proeminência é dada ao conceito posto em dúvida 
Cadernos de Estudos Lingüísticos 48(1) - Jan./Jun. 2006

pelo interlocutor, numa espécie de reafirmação, por dois recursos: a silabação e a topicalização. Nos conceitos incluem-se idéias como as de quantidade, tempo, lugar, modo, etc. que podem ser objeto de relevo por diversas razões, como se pode ver em (12 e 13), em que a proeminência foi estabelecida pela altura da voz. Em determinados momentos o falante coloca um conceito em relevo para marcá-lo não apenas como importante na estrutura ideacional/cognitiva do texto, mas também para chamar a atenção para o fato de que ele está sendo usado com uma significação diferente do usual. É o que temos em (9) com o relevo em "enGAnos", para sugerir que não foram enganos, porque foram propositais para beneficiar alguém num dado concurso.

(8) I2- .......por exemplo, pitanga, tem uma vizinha ali que tem um de pitanga que é uma SENSA-CIO-NAL, o tamanho das pitanga(s), puxa! Aquilo é uma beleza....(NURC-D2 POA 291: 552-554)

(9) L2- houve uma série de irre/éh:: de irregularidades... nas lis/na apresentação da lista de classificação irregularidade foi engano... no no no fazer... na confecção da lista... de de aprovados hou/houv/ começaram a haver alguns enganos... então o pessoal que mand/ entrava com mandado de segurança... dizendo que foi contado pontos errados... enGAnos simples comuns eh aritmética (às vezes) de somar o número de pontos... então eles entraram com mandado de segurança... anulando aquela lista de classificação... e então havia publicação de outras... e assim foi indo e:: e a::... de acordo com o edital a validade é dois anos DA publicação... dos resultados... da lista de aprovados... então com a:: com esta... com este recurso de mandado de segurança... não foi propriamente o recurso foram coisas que realmente aconteceram...(D2 SP 360: 589-604)

(10) outra pergunta foi a seguinte... existe diferença ... entre... ciência do normativo e... uma ciência normativa?............................................. expliquem com suas próprias palavras 0 que foi que vocês encontraram? existe diferença? HÁ diferença? ou não? ... talvez seja a pergunta mais difícil de todo o capítulo... ( NURC-EF REC 337: 470-487)

(11) I2- Negócio sério. É, eu, eu, eu, eu tive assim uma, algumas coisas, exóticas, macaco, uma ocasião.

I1- Como é macaco?!

I2- Ma-ca-co, na Amazônia tem um tipo de macaco lá que se prepara e aí, eu confesso, toda serenidade, provei e achei bom, não é ruim não ((risos)) (NURC-D2 POA 291: 250-255)

(12) Inf. ............................ nesse estágio ele não::... assiste aula... apenas ele faz... o:.... a parte corriqueira do ambulatório... ele atende os doentes... medica... é supervisionado sempre por um professor ou por um médico no caso... e:..... depois ele vai fazer... o seu:.... relatório... dos doentes que ele atendeu quais os diagnósticos tratamento que ele fez por esse relatório então nós fazemos o::.... vamos dizer o gabarito do:.... do estudante se ele foi bom estudante se ele teve... uma:: uma freqüência boa ou se ele foi aceito ou se ele foi um estudante relapso... (agora) QUANdo eles são estudante $\mathrm{d} /$... nos primeiros anos que eles não ainda têm contacto com o doente... eles apenas assistem aulas...tanto teórica como prática... alguns fazem pesquisas que gostam... então eles entram mais ana área da pesquisa... outros apenas... ficam somente na parte clínica... do tratamento pro doente né? (DID SSA 231:424435, p.14) 
(13) Inf. .................. e finalmente... a terceira perspectiva... a filosófica... ou como nós colocamos... filosofia do direito... o que estuda?... estuda o fenômeno jurídico... a-profundan: do... a partir... dos conhecimentos... científicos... ou da própria dogmática... do direito... esse fenômeno/... então novamente... a filosofia do direito...é nada mais do que... um tipo de estudo... um conhecimento... que aprofun:da mais: aqueles outros DOIS... seja um conhecimento num é sociológico... ou conhecimento... normativo... lógico-normativo... vamos dizer que o conhecimento... da filosofia do direito num é? sobre o fenômeno jurídico... ele transcen:de... à pesquisa... isso significa... daí não haver o rigor no estudo... ele vai além: de... ele diz como o comportamento deve ser... independente do que ele é.. como ele deveria ser... vocês realmente estão percebendo gente? tão compreendendo mesmo? (EF REC 337: 434- 450)

\section{2- Relevo incidente sobre a maneira como o produtor do texto quer que seu interlocutor} considere os conceitos e modelos cognitivos ativados no texto. Essa maneira geralmente é dada por quantificadores, intensificadores e advérbios que têm natureza aproximada e, na língua oral, respondem por 32,97\% das ocorrências de proeminência pela altura da voz (Cf. Travaglia-1999, p. 96). Em (14), num momento em que o falante desenvolve sobre a qualidade de comidas feitas por $\mathrm{X}$ ou $\mathrm{Y}$, dá relevo ao fato de ser bem feito, usando a repetição de "bem feito" responsável pelo conceito de qualidade e ao mesmo tempo repete e alonga o intensificador "muito" dando relevo ao fato de que ele quer que se considere está qualidade em um alto nível.

(14) I2- ...... Como é o nome daquele ali em cima do Floresta Negra, acima, ah, tu entras na Galeria, Floresta Negra fica aqui à esquerda tu tens uma escada, tem um restaurante ali em cima, eu comi ali foi um coelho, uma ocasião, mu:::ito bem feito, mu:ito bem feito... (NURC-D2 POA 291: 361-365)

3.3- Relevo incidente sobre relações entre elementos e partes do texto, geralmente marcadas no texto por preposições, conjunções, conectores (marcadores) e operadores argumentativos e respondem por 11,47\% das ocorrências de relevo pela altura da voz (Cf. Travaglia, 1999, p. 96). No exemplo (6), a pronúncia de "aliás" com maior altura de voz, tem-se o relevo dado pelo operador argumentativo à relação entre argumento (não gostar de pescar) e tese (não precisa/ deve ser convidado para pescar). Na verdade, o argumento recebe um relevo especial pelo uso do tipo de operador como já foi comentado. Em (15), a relação de inclusão recebe proeminência; em (16), a oposição entre os vários elementos que deve haver na escola e o elemento que o informante considera como realmente importante na escola que é a sala de aula. Ele dá relevo à sala de aula pela altura da voz, pelo recurso lexical (importante), pelo uso do expletivo (é que) e pela repetição, num acúmulo significativo de recursos para dar proeminência à idéia de que "a sala de aula é que é importante" e não os outros elementos que citou, mas considera secundários.

(15) ....... porque a sociologia do direito por exemplo ela não estuda somente ... ela estuda a lei mas NÃO somente a lei TAMBÉM a lei... em relação: ou em adequação com a própria realidade... social... então João ...se... não é? na próxima avaliação... eu pergunto... ou eu AFIRMO... eu posso afirmar também... sociologia do direito é igual a sociologia... jurídica... corre:to... ou errado... justifique sua resposta vamos supor... (NURC-EF REC 337: 170177) 
Cadernos de Estudos Lingüísticos 48(1) - Jan./Jun. 2006

(16) Inf. pro estudante... ter o seu recreio ter a sua hora de descanso... ahn?... prática de esporte... então nós (precisamos) de ter:: as (pérgulas) com todos os tipos de esportes prá ser praticado... piscina prá natação que é muito importante prá:: saúde.. biblioteca né?... ahn e setor médico também e odontológico que precisa numa escola né?... fora a parte de::: diretoria né? salas de diretores... secretárias né?... vice-diretores... de escola... isso é um setor a parte na escola

[

Doc. (essa parte de...)

Inf. MAS o importante É SALA DE AULA eu acho que o importante é sala de aula e:: esporte né? (NURC-DID SSA 231:254-262, p. 9)

3.4- Relevo incidente sobre um fato, um estado de coisas, uma avaliação, geralmente expressos em um trecho que recebe relevo graças a recursos diversos. Em (17), o fato de considerar como o mais exótico um dado prato servido em um dado lugar em oposição a outros já referidos é marcado pela repetição, pela altura da voz, pela entonação e pelo uso dos expletivos "foi" e "mesmo". Em (18), o relevo feito pelo recurso lexical "vamos grifar" incide sobre o fato de a diferença estar somente em se levar em conta a realidade social. Em (19), o falante usa o marcador conversacional "olha aqui" para destacar o fato de ele não acreditar que alguém possa duvidar da qualidade da sardinha. Em (20) e (21), o falante usa o mesmo marcador conversacional "olha"/“óia" para pôr em relevo respectivamente que ele faz um bom churrasco e que ele considera engraçado o que vai contar a seguir. Em (22), (pelo contorno entonacional dado à palavra monstruosidade que é pronunciada num ritmo lento, quase com silabação) o falante dá proeminência a sua avaliação negativa do fato de comprar remédios sem receita.

(17) I2- Mas exótico, exótico mesmo, foi na casa do cônsul japonês aqui em Porto Alegre... há uns três anos atrás mais ou menos eu fui convidado prum almoço assim muito íntimo e a senhora... ela que preparou... eram olhos de peixe... a sopa. (NURC- D2 POA 291: 272275)

existe análise também... eu diria que existe até mes:mo... um olhar assim um tanto voltado à realidade... mas... fazer uma análise... um estudo sistemático... somen:te... aí é que está a diferença... somente... vamos grifar... somente levando em consideração a realidade social... em adequação.. à lei por exemplo... ao direito... vigente...(NURC-EF REC 337: 358-364) (SOBRE UM MODO DE PESQUISA UM MODO DE AÇÃO)

(19) I2- .... Com a, a, a, olha aqui, alguém duvida, por exemplo, eu, já, falando sobre o aspecto de comida de novo... mas alguém duvida da, da qualidade da sardinha brasileira. Alguém duvida? (NURC-D2 POA 291: 1290-1293).

(20) I1- Olha eu me limito a faze(r) um bom, bom! Um churrasco (superposição) churrasco. Mas eu posso fala(r). (NURC-D2 POA 291: 201-202).

(21) L- ... i que era hora di eli vim aqui, intão eu saí c'a minha mãe. Intão, olha só, mais óia, achu qui issu é... gozadu até purque é au contráriu, né, as coisas... (NURC-DID SP 59: 135-137, pág. 4)

(22) I2- ....... eu acho que é errado que compre inclusive um melhoral sem receita médica... eu acho isso uma monstruosidade, entretanto muito mais do que o melhoral até mesmo, antibióticos se compra sem receita médica.(NURC-D2 POA 291: 642-643) 
3.5- Relevo incidente sobre elementos da interação. Em (23), por meio do uso de parênteses, a professora pede uma atenção naquele momento da interação.

(23) ........ porque eu encontrei... uma definição... não é? lendo agora um trabalho bem recente... uma definição... na qual... mostra realmente/ não está no livro porque é recentíssima é uma é uma definição... não é? ligando as três perspectivas... de um artigo de mil novecentos e oitenta e seis... então atenua um pouco... a hostilida:de que existe entre a tre três perspectivas... que é a seguinte... eu vou lê João depois... falamos... talvez até coloque para vocês... isso é uma maneira também de pedir... que prestem atenção... não é? esse... trechinho ou essa citação... de um artigo... diz assim aspas mesmo podem colocar... não quer dizer não escrevam não eu digo colocar nas cabeças de vocês... ou à medida que vão usu que vão ouvindo (NURC-EF REC 337: 277-290)

3.6- Relevo incidente sobre um determinado tipo de elemento dentro do texto. Em (24) e (25), temos o relevo do tipo figura e fundo incidindo sobre elementos da narrativa. Conforme a legenda abaixo, pode-se observar que:

a) aparecem como figura (primeiro plano): os episódios da trama (complicação e resolução), marcados sempre pelo aspecto perfectivo (Cf. Travaglia-1991) e que;

b) aparecem como fundo (segundo plano): os elementos de orientação (descrições de cenários e personagens e/ou especificação de ações que compõem um pano de fundo para a trama) e de avaliação (considerações, explicações, comentários sobre os fatos da trama), marcados pelo aspecto imperfectivo (Cf. Travaglia-1991) ${ }^{8}$.

- itálico - fundo (orientação)

- sublinhado - fundo (avaliação)

- negrito - figura

- [ - início do trecho a ser considerado.

- letra normal - trechos de fala, marcadores e outros.

Observe-se ainda que, em (25), a moral da história, que é um tipo de elemento comum na superestrutura da fábula, aparece em proeminência, com um tipo de letra diferente e maior, além de estar, no livro, destacada em um quadro verde musgo com bordas negras sobre um fundo branco. Evidentemente estes recursos gráficos colocam a moral em relevo, por ela ser vista como a conclusão da argumentação que sempre se considera como fundamental.

(24) I1- Olha eu me limito a faze(r) um bom, bom! Um churrasco (superposição) churrasco. Mas eu posso fala(r) da, da experiência engraçado, tem pessoas que tem um, um, um, em termos gastronômicos um, um, uma, um talento uma habilidade, impressionante, [ a minha avó era assim, ela qualque( $r$ ) prato, podia se( $r$ ) o mais complexo, de gosto mais estranho ou exótico possivel, ela detectava tempero por tempero e depois reproduzia fazia eu sei que, ãh, quando chegô, praticamente os primeiros vidros de Ketchup que chegaram dos Estados Unidos era material importado, meu tio trouxe pra casa a prova daquilo,

\footnotetext{
${ }^{8}$ Para alguns estudiosos o constraste entre figura e fundo é marcado pelas formas verbais: fundo (presente do indicativo e pretérito imperfeito do indicativo); figura (pretéritos perfeito e mais-que-perfeito do indicativo)
} 
Cadernos de Estudos Lingüísticos 48(1) - Jan./Jun. 2006

isso em mil novecentos e vinte ou qualque( $r$ ) coisa assim e a velhinha (ininteligível) todo mundo elogiou o vidrinho tal e coisa, ela ficou quieta, no dia seguinte, o Ketchup estava na mesa, hum, também provou, etecétera, etecétera e ela então veio com a notícia que aquele Ketchup que estava sendo servido era ela que tinha feito, o outro, ela tirou, botou o dela e serviu. Aí o pessoal, não é possível, foram provar era o mesmo.

I2- Sensacional, né?

I1- Impressionante,é... ela fazia isso, ela tinha, pegava o negócio assim, mas analisava o negócio inteirinho, sabe que é uma coisa assim muito rara. É incrível! Eu digo talvez os temperos não fossem os mesmos, mas ela conseguia, ia provando, ia botando mais um pouquinho e pá, e encontrava, o mesmo gosto e a mesma aparência, isso também. (NURC-D2 POA 291: 201224)

\section{(25) A ONÇA E A HIENA}

Rachel Gazolla ${ }^{9}$

Era uma vez uma onça que descansava soberba à sombra de uma árvore, quando recebeu a visita de uma hiena. Ela se aproximou cheia de mesuras do forte animal:

_ Ó belíssima onça, rainha majestosa, como tem passado, Sua Soberania? Vim trazerlhe um grande ramo de palmeira para proteger Sua bela juba do calor! - disse servilmente.

A onça já tivera um encontro desagradável com a hiena na época de fome do inverno anterior. Na ocasião a hiena sequer a cumprimentara, porque ela não tinha restos de caça para lhe dar. Pareceu-lhe muito falsa a hiena, que continuou solícita ao seu lado e passou a abaná-la enquanto olhava um pedaço de caça ali ao lado. A onça, que estava bem atenta, disse-lhe para ver-se livre daquela companhia:

__ Hiena, não desfrutarás do resto de minha caça, que é o que realmente queres. Desaparece! Do contrário, serás minha próxima refeição.

A hiena, espantada e sem graça soube que nada mais de bom poderia esperar. A onça pensou com seus botões: "Hiena tonta! Pensou que eu acreditaria na sua mudança de sentimentos da noite para o dia! Tão tola quanto falsa! Que se cuide daqui por diante..."

Mas faz parte da natureza da hiena ser assim. Na próxima oportunidade que teve, voltou a adular o grande animal, que acabou por morder-lhe o pescoço.

\begin{tabular}{c}
\hline MORAL DA HISTÓRIA \\
Os limites da inteligência de um falso \\
aparecem nos exageros de suas mesuras.
\end{tabular}

3.7- Relevo incidente sobre elementos da organização textual. Em (26), o marcador "olhe" vai colocar em relevo um parênteses que a falante faz no fluxo de desenvolvimento do tópico para deixar marcado algo que ela não quer esquecer de dizer: que tudo o que está dizendo deve ser visto dentro de uma "realidade social". Em (27), a falante usa recursos para focalizar a atenção dos interlocutores sobre algo que já disse anteriormente. Neste exemplo temos casos de

${ }^{9}$ ANDRADE, Rachel Gazolla de. Fábulas nuas e cruas/ Rachel Gazolla. São Paulo: Parábola Editorial, 2005. pp. 19-20. 
dêixis textual como recurso de focalização em partes do já dito, mas esta pode ser usada também para focalizar elementos que se vai dizer em determinadas partes do texto: "como dissemos/diremos; demonstramos/demonstraremos; explicamos/explicaremos; etc. no parágrafo/nos exemplos/etc. anterior/ acima/abaixo/a seguir/etc.”. Em (27), este tipo de recurso é usado para destacar o que a falante já desenvolveu justificando assim o tratamento superficial ("então vamos passar por cima disso") que ela propõe dar ao subtópico. Em (28), por meio da proeminência pela altura da voz no marcador discursivo de início de tópico ("BOM"), o informante destaca que, após alguma hesitação, vai iniciar o desenvolvimento do subtópico solicitado pelo documentador,

(26) ......... exa:to que é a ética do dever ser do ou do que deveria ser ainda mais entendeu? ((intervenção de locutor acidental)) olhe antes que eu esqueça um parêntese... na realidade social talvez eu esqueça isso de futuro... por isso vou dizendo loga agora... o ser e o deve ser na realidade social... eles se: ãh!... complementam andam juntos (NURC-EF REC 337: 580-587)

(27) ....... isso eu expliquei... eu a acho que na segunda ou terceira aula... mais do que as religio:sas mais do que: as regras morais etecetera... eu acho que expliquei isso... então vamos passar... por cima disso... ainda um outro ponto... não é? a segunda resposta vocês têm de uma maneira... um pouco rápida porque leram... eu volto somente se alguém tiver alguma pergunta... (NURC-EF REC 337: 80-86)

(28) Doc.- é isso o que mais chama atenção por exemplo quando a senhora olha para o filme assim a não ser as cenas e o conteÚ:: do o que mais impressiona a senhora?... Inf. não sei o que te responder o que mais me impressiona?... ah nem sei... BOM eu acho que para mulher o que mais chama atenção são as cenas lindas os locais que que passam o mais a roupa né?... eu acho que mais é a roupa maquiagem cabelo... as artistas... parecem umas bonecas né? quando trabalham em filme ((risos))... fala (NURC-SP DID 234 . 349-357)

\section{8- Relevo incidente sobre informações principais ou secundárias e sobre informações novas.}

3.8.1- Informações principais. Giora (1983) apresenta evidências de que a posição final de segmentos textuais (parágrafo, estrofe, capítulo) é a posição padrão para a informação vista como principal e que ela é aí colocada por razões cognitivas e facilitadoras do estabelecimento de coesão entre segmentos do texto para além da frase. Desse modo, pode-se considerar a colocação de uma informação nessa posição como um modo de relevo da mesma, para que permaneça na consciência do interlocutor. A idéia de que a informação mais importante tende a ser colocada no final do texto ou de segmentos seus também é defendida por Fries (1992), para quem este posicionamento facilita a interação entre os interlocutores. Van Dijk (1992), no capítulo "Estruturas de Modelos e Relações Funcionais no Discurso", falando da linearização das informações, faz perceber que a categoria de texto pode influenciar na colocação das informações mais importantes no texto. Assim, na notícia de jornal, os objetos ou eventos mais importantes são apresentados primeiro; já em textos argumentativos e dissertativos as conclusões tendem a ir para o final. Kappel (1998), estudando a relação desse posicionamento da informação principal 
Cadernos de Estudos Lingüísticos 48(1) - Jan./Jun. 2006

em final de segmento tópico ${ }^{10}$ com qualidade de texto e legibilidade do mesmo, em um corpus de redações de vestibular, deixou evidente a preferência pela colocação da informação mais importante no final do segmento tópico, tendo em vista a legibilidade do texto e sua consideração como bem construído na avaliação feita pelas bancas de correção. Desse modo a informação mais importante é geralmente focalizada no final de segmentos tópicos, posição em que ganha proeminência dentro do processamento cognitivo. Em (29), transcrevemos uma das redações analisadas por Kappel (1998), onde os elementos em negrito representam a informação principal e a alternância de tipos de letras delimitam os segmentos tópicos (que não necessariamente coincidem com segmentos formais: parágrafos, estrofes, capítulos, etc), segundo a análise da autora.

(29) Redação de vestibular $-1^{\circ}$ semestre de 1997

Universidade Federal de Uberlândia

Tema: A favor da existência de vida inteligente na Terra

Nota: 16,65 (=92,5\% do total de 18 pontos)

"Inteligência: conceito relativo"

"Observando-se o mundo contemporâneo, percebe-se que a humanidade conquistou grandes progressos tecnológicos, culturais e grandes feitos em todos os campos do conhecimento. Não obstante este quadro auspicioso, essa mesma humanidade, gradualmente, caminha em direção ao seu próprio fim, o que inevitavelmente ocorrerá, caso persista a devastação do meio ambiente e do planeta como um todo. Será a humanidade então inteligente?

Frise-se, primeiramente, que existe inteligência no planeta Terra. É impossível não considerar o homem como um ser dotado de inteligência. O raciocínio, a criatividade, a capacidade de abstração e principalmente a capacidade de superar obstáculos e progredir provam que há vida inteligente na Terra. Além disso, cresce cada vez mais o número de pessoas preocupadas com os perigos que o próprio homem representa para o planeta.

Ora, mas se há vida inteligente no planeta, quais os motivos que levam à contínua devastação do planeta? São os velhos motivos de sempre: a ganância desmedida, o lucro e a riqueza como primordiais, acima de quaisquer outros valores.

Em síntese, não é uma questão de se perguntar se há inteligência ou não no planeta Terra. Inteligência não é sinônimo de virtude, de bondade ou de sentimentos nobres. O que deveria ser questionado é se, no planeta Terra, existe ética, fraternidade, escrúpulo e amor pelo planeta."

A proeminência sobre informação principal e nova acontece em situações, por exemplo, de precisão sobre qual informação é válida. Suponha-se que algo foi feito (deixar uma máquina ligada indevidamente) em uma dada instituição (hospital) e é preciso saber quem foi, para estabelecer responsabilidades. Uma discussão se instaura e num dado momento um dos interlocutores que tem evidências sobre o autor da ação, buscando encerrar a discussão, diz o texto de (30a) abaixo com maior altura de voz no elemento em negrito. Na língua oral ou na escrita, o mesmo efeito seria conseguido pelo uso de um expletivo (ser .... que/quem) como em (30b).

\footnotetext{
${ }^{10}$ Tal como definido em Jubran, Travaglia et alii-1991.
} 
(30) a- Antônio deixou o tomógrafo ligado. (Pela altura da voz, por meio de acento focal) b- Foi Antônio quem deixou o tomógrafo ligado.

3.8.2- Informações secundárias. A informação secundária, por razões cognitivas e interacionais, dificilmente será objeto de proeminência, mas é objeto de rebaixamento. Em Travaglia (1991: item 6.3.6), verificamos que as orações reduzidas, ou seja, com formas nominais do verbo (excetuando o infinitivo, quando forma orações subordinadas substantivas) veiculam informações secundárias. Do mesmo modo, em Travaglia (1996:155), apresentamos evidências de que as orações subordinadas adjetivas também apresentam informações secundárias. A nosso ver é o que temos em (31): um rebaixamento, por meio da oração adjetiva, porque a informação nem mesmo era necessária, uma vez que, pelo co-texto, já se sabia que o ketchup estava sendo servido, como pode ser observado no exemplo (24) de que o exemplo (31) é parte. Em (32), as orações reduzidas introduzem informações secundárias na descrição. Assim "executando", "desenhando", "separando-se", "marchando" e "reunirem-se" dão detalhes de como "Os dançantes continuavam no compasso marcial da polaca,". "Batendo" e "arrastando" apenas indicam o modo como "faziam um barulho seco, enorme". "Procurando" é apenas um detalhamento de "moviam-se". "Abraçados" é especificação do modo como "passeavam". Observe-se que os pretéritos perfeitos do indicativo em itálico introduzem elementos centrais da descrição enquanto as formas nominais em negrito trazem detalhes vistos como secundários em relação a eles.

.o Ketchup estava na mesa, hum, também provou, etecétera, etecétera e ela então veio com a notícia que aquele Ketchup que estava sendo servido era ela que tinha feito, o outro, ela tirou, botou o dela e serviu. Aí o pessoal, não é possível, foram provar era o mesmo (NURC-D2 POA 291: 213-217).

(32) A Dança dos Colonos Alemães

Graça Aranha ${ }^{11}$

Os dançantes continuavam no compasso marcial da polaca, executando variadas figuras, ora desenhando meias-luas, ora separando-se em alas, marchando frente a frente, ora fazendo evoluções de homens e mulheres, separados, para se reunirem depois de diferentes voltas. Os movimentos eram tardos e pesados, dentro dos sapatos grossos e ferrados, batendo fortemente os pés no assoalho, arrastando-se com esforço, faziam um barulho seco, enorme, que dominava as vozes dos instrumentos. Quando a contradança parava, os pares voltavam-se num mesmo instante como por uma combinação mágica e todos livres se moviam vagarosamente, procurando os bancos encostados às paredes das salas ou aos cantos das janelas. Muitos saiam até ao terreiro, para se refrescar; namorados passeavam ali no escuro, abraçados; velhos fumavam o seu cachimbo, resmungando conversas prequiçosas, até que de novo a música dava o sinal e todos voltavam à sala, em ordem, sem o menor embaraço, passando a dançar automaticamente, de charuto ou cachimbo ao queixo e chapéus na cabeça.

3.9- Relevo incidente sobre um certo tipo de informação, como acontece nos exemplos (1) e (2) em que temos rebaixamento de trechos com o fim de minimizar informações menos

\footnotetext{
${ }^{11}$ Apud OLIVEIRA, Cleófano Lopes de. Flor do Lácio. São Paulo: Saraiva, 1965. p. 123.
} 
Cadernos de Estudos Lingüísticos 48(1) - Jan./Jun. 2006

favoráveis ao anunciante das publicidades face a seu objetivo de vender seu produto (1) ou serviço (2).

3.10- Relevo incidente sobre um modo de dizer. É o que temos nos exemplos (33) e (34) abaixo. Em (33), a falante (uma professora) dá relevo a sua dúvida sobre o verbo a usar (existir ou haver), embora os dois tenham o mesmo significado. Sua opção recai em "existir", tanto que a seguir ela o usa duas vezes sem qualquer relevo. Em (34), a mesma falante põe em relevo a "correção" ou alternativa que coloca, ao ficar em dúvida sobre como dizer que ela quer que o aluno se baseie no texto para responder. Em (15), ao dar proeminência a "AFIRMO", a falante destaca a forma como pode construir uma questão da prova, opondo o verbo afirmar ao verbo perguntar, tanto que depois diz "eu posso afirmar também”.

(33) a- ........ você tá entendendo João agora a diferença?... não é que o estudo não seja sério... é sério também como eu falei antes... HÁ sistematização EXISTE_ sistematização... existe análise também... eu diria que existe até mes:mo... um olhar assim um tanto voltado à realidade... (NURC-EF REC 337: 355-360)

(34) ...... são as três:... num é? perspectivas... elas são:... complementa:res ou não: Eduardo? há um sentido de complementariedade ou não ou são assim... cada uma que se vire e: que não olhe a outra... você diria ((intervenção de locutor acidental)) é... uhum... Arnaldo não é? faz uma... complementação NO TEXTO ou PELO TEXTO há existe complementariedade... bem nós VA:MOS não é? admitir... aqui... em aula... que: existe uma: complementariedade entre esses três saberes... ou três conhecimentos... (NURC-EF REC 337: 133-140)

\section{CONSIDERAÇÕES FINAIS}

Como se pode observar, o relevo (proeminência ou rebaixamento) pode incidir sobre diversos tipos de elementos no texto, relacionados ao desenvolvimento do tópico em termos de conteúdo ou de forma para este desenvolvimento. Esse relevo, ocorra por razões ideacionais/ cognitivas, emotivas ou da interação, tem sempre a função de atuar sobre o interlocutor, de acordo com os objetivos do produtor do texto em cada interação específica.

Não pretendemos ter sido exaustivos no levantamento dos elementos sobre os quais o relevo incide, mas nosso objetivo foi tão somente mostrar que o relevo atinge elementos de natureza e extensão variadas e que isto tem uma importância no desenvolvimento do tópico discursivo que não se pode desconsiderar. Nos próximos passos, parece-nos, a atenção deve ser dada a fatos como:

a) a correlação entre o tipo de elemento objeto de relevo e o tipo de recurso estabelecedor do relevo;

b) a correlação entre o tipo de elemento objeto de relevo e a função do relevo

uma vez que anotamos, ainda um tanto intuitivamente e assistematicamente alguma tendência de correlação nestes aspectos. 


\section{REFERÊNCIAS BIBLIOGRÁFICAS}

FRIES, P. H. (1992). The structuring of information in written english text. Language Sciences, vol. $14, \mathrm{n}^{\circ} 4$, p.461-488. Oxford: Pergamon Press Ltd.

FUCHS, A. (1987). Aspecto verbal e dêixis. Brasília: Universidade de Brasília, cópia de inédito. 36 p.

GIORA, R. "Segmentation and segment cohesion: on the thematic organization of text. Text, vol.3, p.155-181.

JUBRAN, C. C. A. S.; TRAVAGLIA, L. C.; et alii. (1991) "Organização tópica da conversação" in ILARI, Rodolfo (org.) Gramática do Português Falado Vol. II: Níveis de análise lingüística. Campinas, Ed. da UNICAMP, 1992: 357 - 447.

KAPPEL, I. B. A. (1998). Segmentação textual, coesão e distribuição informacional na organização tópica do texto. Dissertação de mestrado. Uberlândia, UFU/ILEEL: 165 p.

TRAVAGLIA, L. C. (1991). Um estudo textual-discursivo do verbo no português. $330+124$ p. Tese (Doutorado em Lingüística) - Campinas, SP: IEL / UNICAMP, 1991.

. (1996). Gramática e interação - Uma proposta para o ensino de gramática no $1^{o}$ e $2^{o}$ graus. São Paulo: Cortez.

. (1999). "O relevo no Português falado: tipos e estratégias, processos e recursos" in NEVES, Maria Helena de Moura (org.). Gramática do Português Falado Vol.VII: Novos estudos. São Paulo: Humanitas / FFLCH-USP; Campinas,SP: Ed. da UNICAMP, 77-130.

VAN DIJK, T. Cognição, discurso e interação. São Paulo: Ática. 